\title{
Limites e Possibilidades da Interação Sociopolítica entre Sociedade e Câmara dos Deputados pelo Portal Eletrônico e-Democraciai
}

Limits and Possibilities of Sociopolitical Interactions Between Society And Chamber Of Deputies' Through Electronic Portal of e-Democracy

Portal Electrónico e-Democracia: Límites y Potencial de Interacciones Sociopolíticas entre la Sociedad y la Cámara de Diputados

André Costa Monteiro Leonnel

Graduação em Administração Pública pela Universidade Federal de Lavras Discente do Departamento de Administração e Economia da Universidade Federal de Lavras http://lattes.cnpq.br/4124803233532334 https://orcid.org/0000-0003-4355-0371 andremonteiroleonel@gmail.com

Dany Flávio Tonelli Doutorado em Administração (Concentração em Organizações, Mudanças e Gestão Estratégica) pela Universidade Federal de Lavras. Professor Adjunto do Departamento de Administração e Economia da Universidade Federal de Lavras http://lattes.cnpq.br/1549447568023040 https://orcid.org/0000-0002-4307-6430 danytonelli@dae.ufla.br

Paulo Henrique Montagnana Vicente Leme Doutorado em Administração pela Universidade Federal de Lavras Professor Adjunto do Departamento de Administração e Economia http://lattes.cnpq.br/8203011955597072 https://orcid.org/0000-0003-4174-5642 paulo.leme@dae.ufla.br

Júlia Moretto Amâncio Doutorado em Ciências Sociais (Concentração em Cultura e Política) pela Universidade Estadual de Campinas (2013) Professora Adjunta do Departamento de Administração e Economia da Universidade Federal de Lavras http://lattes.cnpq.br/6531186476207277 https://orcid.org/0000-0002-3378-4054

julia.moretto@dae.ufla.br

Resumo. As novas ferramentas digitais tornam-se cada vez mais populares afetando as condições de participação da sociedade nos processos decisórios do Estado e influenciando o contexto democrático. Sob o prisma da análise científica é necessário exercer um olhar crítico do processo, de modo que ele possa ser considerado a partir das suas potencialidades e também das suas limitações. Nesse contexto, 0 principal objetivo foi investigar os limites e as possibilidades do portal e-Democracia na realização de seu propósito de promover a interação entre a Câmara dos Deputados e a sociedade. Para tanto, realizou-se investigação qualitativa, de natureza exploratória, com adoção do método estudo de caso. O portal eDemocracia da Câmara dos Deputados tem o propósito de permitir à população espaço para colaborar sobre temas relativos ao processo legislativo. Após a coleta de dados, o corpus (reunião de documentos, anotações de observação e transcrições de falas realizadas em grupo de foco) foi submetido à análise de conteúdo. Os resultados demonstraram que uma das principais limitações do eDemocracia está relacionada com a participação restrita dos deputados, o que gera certo sentimento de frustração dos usuários da sociedade. Todavia, os servidores da Câmara responsáveis pelo eDemocracia demonstraram acreditar no potencial da ferramenta eletrônica e no ecossistema de participação proporcionado por ela para o fortalecimento da democracia.

Palavras-Chave. Democracia Digital; Participação; Sociedade; Cidadania; Governo Digital.
Abstract. The new digital tools are becoming increasingly popular since they affect the conditions of participation by society in the decision-making process of State and affect the democratic context. From the perspective of scientific analysis, it is necessary to exercise a critical look at the process, in such a way that it may be considered by its potential as well as by its limitations. In this context, the main objective was to investigate the main limits and the possibilities of the web portal e-Democracia in the fulfilling of its purpose of promoting interaction between Chamber of Deputies and society. Therefore, a qualitative investigation of exploratory nature was conducted, adopting the case study method. The Chamber of 'Deputies' e Democracia Web Portal has the purpose of giving the general population space to collaborate on themes related to the legislative process. Following data collection, the corpus (ensemble of documents, observation notes, and transcripts from focus group talks) was submitted to content analysis. The results show that one of e-Democracia's main limitations is related to the limited participation of the Deputies, which generates frustration in users from society. However the Chamber of Deputies workers who is responsible for e-Democracia, believe the electronic tool's potential and the participation ecosystem resulted from it have the potential of strengthening the democracy.

Key-words. Digital Democracy; Participation; Society; Citizenship; Digital Government.
Resumen. Las nuevas herramientas digitales son cada vez más populares, ya que influyen en las condiciones de participación de la sociedad en el proceso de toma de decisiones del Estado y afectan el contexto democrático. Desde la perspectiva del análisis científico, es necesario tener una visión crítica de proceso de toma de decisiones, de manera tal que pueda ser considerado tanto por su potencial como por sus limitaciones. En este contexto, el objetivo principa planteado aquí fue investigar los principales límites y las potencialidades del portal web e-Democracia en el cumplimiento de su propósito de promover la interacción entre la Cámara de Diputados y la sociedad. Por lo tanto, se realizó una investigación cualitativa de naturaleza exploratoria, adoptando el método de estudio de caso. El Portal Web eDemocracia de la Cámara de Diputados tiene como objetivo brindar espacio a la población en general para colaborar en temas relacionados con el proceso legislativo. Tras la recopilación de datos, el "corpus" (conjunto de documentos, notas de observación y transcripciones de las conversaciones de los grupos focales) se envió al análisis de contenido. Los resultados muestran que una de las principales limitaciones de e-Democracia está relacionada con la participación limitada de los Diputados, lo que genera frustración entre la sociedad de usuarios. Sin embargo, los trabajadores de la Cámara de Diputados, que son responsables de e-Democracia, creen que la herramienta electrónica y el ecosistema de participación resultante de ella tienen el potencial para fortalecer la democracia.

Palabras-claves. Democracia Digital; Participación Sociedad; Ciudadanía; Gobierno Digital.

Texto completo em português: http://www.apgs.ufv.br Full text in Portuguese: http://www.apgs.ufv.br

\section{INTRODUÇÃO}

Com invenção do Telégrafo Napoleônico (ótico) no final do século XVIII, a ideia de democracia representativa parecia prestes a tornar-se obsoleta. Bastava que o código utilizado pelos seus operadores fosse aberto para que inúmeras posições pudessem fluir diretamente entre a população e o governo francês. Entretanto, os eventos tomaram outro 
rumo, e o entusiasmo com a possibilidade de uma renovação democrática esvaiu-se no tempo (FARIA, 2014). As possibilidades de conectar Estado e sociedade de modo mais direto renovaram-se com o avanço das Tecnologias de Informação e Comunicação (TIC) nas últimas décadas. Pinho (2011) considera que é instaurado um marco civilizatório, por meio do qual a história passa a ser dividida entre antes e depois da internet. $O$ crescimento exponencial do uso da web refletiu-se no aumento de uso das tecnologias baseadas na rede de computadores interligados para a promoção da comunicação entre 0 as instituições políticas e a sociedade. Mesmo considerando que, no Brasil, o uso da internet para comunicar-se com o governo ainda predomina nas classes $A$ e $B$, seu uso vem crescendo nos últimos anos. De modo geral, $8 \%$ dos usuários utilizam esse canal para comunicar-se com a administração superioratravés de e-mails; $8 \%$ em redes sociais; $8 \%$ em sites institucionais por meio de formulários eletrônicos e bate-papos ou chat, $6 \%$ em fóruns ou consultas públicas nos sites do governo (onde pode ser deixadas sugestões ou opiniões) e $6 \%$ em votações ou enquetesii. Nota-se que a falta de habilidade e a preferência por métodos tradicionais tornam o número de pessoas conectadas às novas TIC limitado. Junto à inovação, ressurgem expectativas de mudanças significativas, gerando impactos, como a quebra de algumas estruturas convencionais de poder e a democratização de informações antes não veiculadas para todos. Entretanto, os indicadores demonstram assimetria de acesso por regiões do Brasil e também o uso limitado da internet para a interação sociopolítica entre Estado e Sociedade.

As novas ferramentas digitais que o Estado faz uso inserem-se nesse contexto. Para Silva (2005), novos meios de comunicação por meio da internet permitem interações mais horizontais entre governos e cidadãos, diferentemente dos meios tradicionais que transmitem conteúdo pronto de forma vertical. É possível identificar diversas iniciativas em todos os níveis da administração superior que procuram estabelecer essa interatividade. Por exemplo, no âmbito do governo estadual, há o portal do Gabinete Digital do Estado do Rio Grande do Sul (Dos Santos et al., 2015) e outras iniciativas que visam à participação democrática (Santos et al., 2014). No âmbito municipal destacam-se as iniciativas de orçamentos participativos digitais (Abreu e Pinho, 2014; Sampaio, 2016). No âmbito federal, o poder legislativo possui o portal e-Democracia da Câmara dos Deputados (Freitas et al., 2015).

De modo geral, essas iniciativas incorporam a proposta de criação de ambientes de interação entre sociedade e governos. Há o propósito de permitir à população um espaço para colaborar ou apenas se expressar sobre temas inerentes aos processos governamentais. Isso relaciona-se com o fato de as novas ferramentas digitais embutirem um discurso modernizante. Assim, elas tornam-se cada vez mais populares e acessíveis e influenciam de algum modo o contexto democrático, uma vez que afetam as condições de participação da sociedade. No entanto, sob o prisma da análise científica, torna-se necessário exercer um olhar crítico do processo de modo que ele possa ser considerado não apenas a partir das suas potencialidades, mas também de suas limitações.

Como apontam Kneuer e Harnisch (2016), embora os avanços oportunizados pelas tecnologias baseadas em internet proporcionarem ferramentas de regime eletrônico, participação e, consequentemente, democracia eletrônica, aspectos ainda pouco estudados dizem respeito a "como" e "por que" os governos têm lançado mão dessas iniciativas. Em meio a esses esforços, compreender aquelas já implementadas pode ajudar a lançar luz sobre a questão. É nesse aspecto que está a principal contribuição do presente artigo, o qual se dedica a investigar uma dessas iniciativas em andamento, o Portal e-Democracia da Câmara dos Deputados, por meio da seguinte questão de pesquisa: quais são os limites e as potencialidades do portal e-Democracia para a promoção da interação sociopolítica entre Câmara dos Deputados e Sociedade? Para isso, o objetivo foi investigar os limites e as possibilidades do portal na realização de seu propósito de promover a interação entre a Câmara dos Deputados e a sociedade. Ao focalizar especialmente as medidas, acredita-se que seja possivel preencher ao menos em parte a lacuna do "como", tecendo algumas considerações que podem ser úteis para acadêmicos e tomadores de decisão ligados às políticas de difusão de tecnologias baseadas em internet.

Para atingir esse objetivo principal foi elaborada uma revisão sobre algumas das principais correntes que delineiam o estado da arte acerca da discussão que relaciona o uso das tecnologias baseadas em internet para a promoção da democracia. Após realizada essa tarefa, o artigo esboça um diagrama analítico sobre democracia digital, o qual serviu de orientação para a avaliação dos resultados. Em termos metodológicos, utilizou-se 0 método de estudo de caso do Portal e-Democracia e foi realizada a análise de conteúdo obtido com base nas categorias identificadas no diagrama analítico. A captação dos dados ocorreu por meio da aplicação do Grupo de Foco, por meio de reuniões que seguiram um roteiro previamente elaborado. A parte seguinte apresenta as relações entre o estudo teórico e os dados gerados nas entrevistas. Também pretendeu-se caracterizar a participação virtual dos deputados e da sociedade no portal e-Democracia e identificar como os conteúdos são gerados e qualificados, de modo a proporcionar a compreensão acerca da relevância das tecnologias de informação e comunicação para as práticas democráticas.

Acredita-se que o estudo de caso do e-Democracia traz relevantes insights para a compreensão desses novos ambientes políticos, assim como dos limites e possibilidades dessa forma de interação sociopolítica. Por fim, é apresentada a conclusão do trabalho.

\section{REFERENCIAL TEÓRICO}

\subsection{Tecnologias baseadas em internet e Democracia}

As tecnologias baseadas na internet têm constituído uma das políticas mais importantes de promoção da inovação das últimas décadas. e suas difusões ocorrem de maneira rápida e generalizada. Termos como "egovernment" e "e-participation" têm adquirido consistência teórica e relevância prática crescente desde a década de 1990 (Kneuer e Harnish, 2016). As maiores promessas da rede residem na exponencial capacidade de comunicação, disponibilização e circulação de informações nunca antes experimentada (Pinho, 2011).

Entretanto, não há uma visão consensual acerca das possibilidades que essas tecnologias oferecem para a construção de regimes democráticos. Há pelo menos duas perspectivas a respeito do assunto. A primeira é otimista e ligada ao "avanço democrático". Ela considera que os policy-inputs adicionais dos grupos da sociedade civil e das instituições econômicas - os quais são possibilitados pelas novas ferramentas de informação e comunicação - contribuem para a consolidação de práticas democráticas (Kneuer e Harnish, 2016). A esse respeito, "(...) o emprego das tecnologias da comunicação e da informação poderia possibilitar maior fluxo de informação, reforçar os laços comunitários, revigorar a participação 
política do cidadão e, por fim, suscitar novas formas de relação entre o público e as instituições do Estado contemporâneo" (Bragatto, 2011, p.148). Dessa perspectiva, a internet é vista como potencializadora de mudanças no cenário do fluxo de informações, o que pode conduzir a maior democratização. Isso leva a novas expectativas em relação à participação política e à aproximação entre sociedade e Estado, capturando cada vez mais informações e demandas para as decisões públicas, o que poderia gerar maior retorno e efetividade para as ações do Estado.

Alguns estudiosos dessa linha de pensamento defendem que os regimes democráticos são os primeiros a introduzirem instrumentos de governo eletrônico como os canais deliberativos de E-participação de maneira mais ampla e sustentável, uma vez que eles permitem que grupos e instituições políticas fortaleçam-se por meio dessas ferramentas.

A segunda perspectiva é menos otimista, visto que tal posicionamento adota posição mais cética ao correlacionar a consolidação de regimes democráticos com a adoção de ferramentas eletrônicas. Existem ciclos de entusiasmos com novas TIC e nem sempre elas atendem os anseios de interações sociopolíticas na forma idealizada, o que frustra o objetivo de inovar os métodos democráticos através das Tecnologias de Informação e Comunicação (Faria, 2014). Ao contrário do que advoga uma grande parte da mídia social e dos estudos científicos, as TIC podem ser usadas como ferramentas de repressão e controle nas mãos de poderes autocráticos. Dessa perspectiva, há uma espécie de seu uso como um meio para promover certa "repressão tecnológica", por meio da qual sugere-se que as tecnologias baseadas na Internet não contribuiriam efetivamente no fortalecimento dos regimes democráticos.

Ao avaliar a adoção dessas tecnologias em governos de países não democráticos, Rød e Weidmann (2015) investigaram as condições sob as quais elas são implementadas e os efeitos que elas produzem. Os autores demonstraram que as preocupações acerca do controle das informações representam um fator relevante que explica o motivo de governos autocráticos utilizarem as TIC. Eles também apresentam evidências que sugerem que a expansão da democracia não está relacionada com a expansão dos serviços de internet (Rød e Weidmann, 2015).

Paralelo a esse debate, outro decorre da análise da relação entre eparticipação e qualidade dos processos de decisão políticas. Mesmo considerando a importância crescente da participação eletrônica, a qual pode produzir um cenário propício para engajamento cidadão, troca de informações e deliberação democrática, ainda permanece incerta a extensão da sua contribuição para a introdução de novos repertórios de ação e melhoria da qualidade da entrega de serviços públicos (Alonso $E$ Barbeito, 2016)

Nessa discussão, é importante resgatar os aspectos fundamentais que caracterizam os regimes democráticos (Dahl, 2001). Garcia (2014, p. 23) resume esses cinco critérios elementares da seguinte maneira: (i) existência de participação efetiva de todos os membros da comunidade que devem ter oportunidades iguais e efetivas para expressar suas opiniões; (ii) igualdade de voto, seguindo a lógica de que todas as pessoas devem ter o mesmo valor e importância em um processo democrático; (iii) entendimento esclarecido, a partir do qual a consciência cidadã deverá ser despertada; (iv) controle do programa de planejamento, segundo o qual os membros da unidade devem ter a oportunidade de decidir as prioridades políticas e ter acesso, de forma transparente, a informações acerca do orçamento público e (v) inclusão de adultos, fundamentada na concepção de sufrágio universal, de forma a evitar exclusões despropositadas de pessoas do processo político.

Tomando os requisitos de Dahl (2001) e a problematização sobre a dificuldade de correlacionar a adoção de práticas de participação eletrônica com consolidação de regimes democráticos, pode-se afirmar que as tecnologias baseadas na internet, embora apresentem potencial para ressignificarem a interação sociopolítica entre estado e sociedade, ainda precisam ser mais bem compreendidas, especialmente acerca de qual é o papel que elas efetivamente realizam. No caso da participação eletrônica, Porwol et al. (2016) apresentam uma proposta bem abrangente de compreensão dessas iniciativas. Os autores partem de uma crítica sobre a inexistência de uma ontologia bem elaborada sobre E-participação, o que dificulta a comunicação e a troca de experiências na introdução de novas iniciativas. O modelo proposto abrange o que eles chamam de facetas essenciais do que é a participação eletrônica, das quais o processo democrático é apenas uma delas. Os demais aspectos envolvem compreendê-la como projeto e, por último, como sistema sociotécnico (Porwol et al., 2016).

Na perspectiva do processo democrático, a participação eletrônica é conduzida por questões relativas à representação, ao engajamento cidadão, à transparência, ao conflito de interesses e construção do consenso, à igualdade política e ao controle comunitário. Para além dela, na concepção de projeto, as questões centrais envolvem o engajamento com uma audiência ampla, a obtenção de opiniões, a consulta aprofundada, a análise de custo efetivo das contribuições e a providência de feedbacks para os cidadãos.

Por fim, na perspectiva de sistema sociotécnico, as questões centrais lidam com aceitação social confiança, segurança, relevância, legitimidade e utilidade; acessibilidade, clareza de conteúdo e responsividade; usabilidade, navegação, organização, eficiência e flexibilidade (Porwol et al., 2016). Percebe-se que é preciso capturar melhor as nuances que moldam o contexto no qual o discurso das tecnologias baseadas na internet contribui para a construção democrática, sendo que seu maior uso não necessariamente impacta em mais democracia e nem as ferramentas de participação eletrônica, e são percebidas apenas a partir da perspectiva de promoção da democracia.

\subsection{Diagrama analítico}

Partindo da análise das relações entre tecnologias baseadas na internet e a promoção da democracia, um desafio que se apresenta é identificar possibilidades e limites de iniciativas reais que propõem fazer seu uso para potencializar a interação entre governo e sociedade. Com o intuito de abordar essa questão, desenvolveu-se um modelo de análise dividido em três categorias: (i) participação virtual; (ii) informação e conteúdo e (iii) tecnologias de informação e comunicação e práticas democráticas. Essa divisão de perspectivas aproxima-se do que foi proposto por Porwol et al. (2016) de avaliação das iniciativas Eparticipativas, a partir das abordagens: processo democrático; projeto e sistema sociotécnico.

\subsubsection{Participação virtual}

A democratização digital estreita a relação entre cidadãos e representantes por meio de plataformas na internet (Freitas, 2015). Outro aspecto discutido por Winkler (2009) e Silva (2005) relaciona-se à mudança 
da natureza da comunicação. Antes do avanço proporcionado pela disseminação da rede, havia um modelo unilateral de apenas poucos emissores de conteúdo para muitos receptores. Atualmente há ambos introduzidos numa dinâmica de circulação de informações de forma mais horizontal, aproximando-os.

Por outro lado, para entender o tipo de atuação, devemos considerar que os governantes podem usar os meios digitais para mostrarem apenas o que eles desejam. Já a sociedade, não consegue ver sentido em discussões políticas de assuntos que não afetam seus interesses pessoais. Portanto, mesmo havendo o intercambio horizontal em termos de informação e diálogo entre os participantes, isso não é suficiente para garantir a efetividade da participação digital (Castells, 2004).

Faria (2014) identificou que cidadãos comuns participantes de fóruns de discussão sentem-se motivados quando estadistas também atuam nesses, de forma direta. Isso amplia a lógica participativa, antes centrada no engajamento de cidadãos comuns para incluir 0 engajamento de agentes políticos. No entanto, muitos governantes não possuem interesse de trabalhar com instrumentos virtuais. Entre os motivos para isso, está a indisponibilidade para assumir compromissos públicos (pois muitas vezes esses, contrariam os que foram firmados com grupos de interesses) e a indisponibilidade para assumir posições que eles não possam honrar posteriormente. De modo mais específico, um dos problemas para dar efetividade às iniciativas E-participativas é a falta de legislação que regulamente a participação digital (Faria, 2014).

A disponibilidade da participação digital está na mesma perspectiva do processo democrático elaborada por Porwol et al (2016), no qualvêm à tona aspectos que dizem respeito à qualidade do engajamento cidadão, à transparência e ao conflito de interesses. No entanto, percebe-se, que o engajamento precisa ser compreendido de maneira ampliada, ou seja, deve partir não apenas do cidadão comum, mas também dos políticos (Faria, 2014). No entanto, os agentes políticos estão inseridos em conflitos diversos de interesses pessoais e partidários, o que dificulta o alcance de efetividade democrática em termos de construção de consensos e do protagonismo comunitário.

\subsubsection{Informação e conteúdo}

É inegável que nunca antes na experiência humana a capacidade de comunicação foi tão expandida (Pinho, 2011). Atualmente, por meio da disponibilização e circulação da informação, gera-se um poder libertário e emancipatório, propiciando o crescimento da criatividade e do conhecimento. Com a Internet a oferta de informações cresce, não apenas a partir de fontes oficiais (Maia, 2000). Com novas plataformas de comunicação o público e os políticos podem interagir de forma mais direta com trocas, consultas e debates, rompendo certos obstáculos burocráticos e gerando conteúdos mais ricos.

Entretanto, em um estudo em que Pinho (2008) investiga alguns portais de governos estaduais no Brasil, o autor mostra que existem algumas limitações a respeito do que é disponibilizado e compartilhado. Como exemplo disso, não fica claro como ocorre o fluxo de opiniões geradas pela sociedade civil para o governo. Não é possível saber se as demandas conseguem chegar a quem tem poder de tomar alguma providência, ou se essas informações perdem-se nos meandros da burocracia e não são processadas como deveriam.
A gestão das informações pelo órgão que as recebe não é uma tarefa simples. Para gerar conteúdo consistente, muitas vezes a instituição precisa envolver outros órgãos e atores. O piloto do portal e-Democracia entre 2009 e 2010 envolveu pelo menos cinco órgãos da Câmara dos deputados: a Secretaria de Comunicação, na integração de sistemas de comunicação da Câmara e mobilização da sociedade para participar no portal; o Centro de Informática, suprindo as demandas tecnológicas para funcionamento da ferramenta; o Centro de Documento e Informação, promovendo pesquisas usadas como base nas discussões do Portal e oferecendo conteúdo informativo; a Consultoria Legislativa, preparando o conteúdo inicial das comunidades virtuais, moderando as discussões e andamentos, filtrando as participações e organizando todo o conteúdo participativo e, por fim, o Departamento de Comissões, o qual tem como função promover a inter-relação do que acontece nas comissões permanentes e especiais da Câmara dos Deputados em audiências públicas com os debates do Portal e-Democracia (Faria, 2014).

Quando o cidadão participa, corre-se o risco de ele não enxergar os resultados ou o direcionamento de suas contribuições nas comunidades virtuais. Algumas informações podem não ser utilizadas por questões da gestão da participação e podem passar despercebidas ou não serem consideradas relevantes para aqueles assuntos especíicos, assim como pode haver filtros de participações com conteúdos impróprios. No entanto, a perspectiva do projeto envolve-se na busca de audiência, na obtenção de opiniões, na sistematização delas e na análise de custo das contribuições, das providências e dos feedbacks (Porwol et al., 2016). Nem sempre a gestão dessas informações é percebida dentro de um processo democrático mais amplo.

\subsubsection{Tecnologias de informação e comunicação e práticas democráticas}

Existe uma reorganização social em curso, devido ao novo ambiente político gerado pelas TIC resultante da mudança na interação política devido à expectativa da democracia mediada pelo computador (Bragatto, 2011). Assim, as ferramentas da internet propiciaram novas relações com a informação e os emissores das mensagens, diferentes das geradas por comunicações tradicionais. Silva (2005) propõe que a democracia digital possui cinco níveis de complexidade: disponibilização de informações; coleta da opinião pública; transparência; processos de discussão colocando a população como agentes de produção política com o governo e a democracia plena - direta e deliberativa.

Ramos Júnior (2007) traduz a reorganização social gerada pelo novo ambiente político como um sistema emergente, pois ocorre de baixo para cima, em um meio democrático e descentralizado, permitindo que seja concretizada a participação de forma direta dos conectados na rede.

Entretanto, um problema diz respeito à exclusão dos grupos que ainda não possuem acesso ou possuem acesso de baixa qualidade aos novos meios de comunicação. Além disso, nota-se que existe uma parcela da sociedade que, mesmo com conexão rede, não possui habilidades com o uso de novas tecnologias. Isso porque possuir um computador com internet não quer dizer que o indivíduo que o opera saiba utilizá-lo adequadamente (Stabile, 2012), =é preciso incentivá-lo a participar politicamente pela web.

Uma contribuição para os indivíduos com dificuldades de acesso à rede, pode vir da compreensão às novas tecnologias, a partir da perspectiva dos sistemas sociotécnicos, assim como propôs Porwol et al. 
(2016). Os dilemas que se apresentam a partir dessa ótica contribuem para problematizar desde a aceitação social das novas ferramentas, até questões relativas à usabilidade, à segurança e à responsividade de tais sistemas. Além da sociedade estar preparada para avançar democraticamente com o uso das TIC, a qualidade, a organização e o conteúdo disponível devem ser adequados para os usuários. Muita tecnologia não é sinônimo de muita democracia, como mostra Pinho (2008) em seu estudo sobre os portais de governo eletrônico no Brasil.

No que concerne especificamente à democracia eletrônica, o que interessa é o fortalecimento da relação entre o governo e o cidadão, e, dentro dessa iniciativa, percebe-se que a falta de conhecimento impede 0 pleno exercício da cidadania, pois ela somente pode ser exercida de forma plena se for assegurado ao indivíduo o acesso às novas tecnologias e à informação democrática e instantânea que somente existe no ciberespaço (Ramos Júnior, 2007, p.4.).

A partir do levantamento bibliográfico e discussões apresentadas, foi possível sistematizar os principais elementos em um diagrama analítico que apresenta aspectos as possibilidades e limitações relacionadas aos temas da participação virtual; do conteúdo e informação e das TIC e prática democrática, apresentado na Tabela 1.

Tabela 1 Diagrama analítico de experiências de democracia digital

\begin{tabular}{|c|c|c|}
\hline Categoria & Possibilidades & Limitações \\
\hline $\begin{array}{l}\text { Participação } \\
\text { Virtual }\end{array}$ & $\begin{array}{l}\text { - Estreitamento das } \\
\text { relações Cidadãos- } \\
\text { Representantes. } \\
\text { - Participação horizontal. } \\
\text { - Superação dos limites } \\
\text { de tempo e espaço para } \\
\text { a participação política }\end{array}$ & $\begin{array}{l}\text { - Participação individualista da } \\
\text { sociedade e seletiva do } \\
\text { Governo. } \\
\text { - Falta de interesses de } \\
\text { parlamentares de participar de } \\
\text { instrumentos democráticos } \\
\text { virtuais, o que enfraquece a } \\
\text { ferramenta para a participação } \\
\text { da sociedade. }\end{array}$ \\
\hline $\begin{array}{l}\text { Conteúdo e } \\
\text { Informação }\end{array}$ & $\begin{array}{l}\text { - Exponencial } \\
\text { capacidade de } \\
\text { comunicação, } \\
\text { disponibilização e } \\
\text { circulação de } \\
\text { informação e criação de } \\
\text { conteúdo mais rico. }\end{array}$ & $\begin{array}{l}\text { - Incerteza do usuário se suas } \\
\text { contribuições serão } \\
\text { efetivamente utilizadas. } \\
\text { - Frustração pela gestão das } \\
\text { informações da participação. }\end{array}$ \\
\hline $\begin{array}{l}\text { TIC e prática } \\
\text { democrática }\end{array}$ & $\begin{array}{l}\text { - Novo ambiente político } \\
\text { mais acessível, direto e } \\
\text { com informações antes } \\
\text { não veiculadas junto } \\
\text { com novas relações } \\
\text { com os emissores das } \\
\text { mensagens. } \\
\text { - Sistema emergente, de } \\
\text { baixo para cima, em um } \\
\text { ambiente democrático e } \\
\text { descentralizado. }\end{array}$ & $\begin{array}{l}\text { - Não basta fazer com que o } \\
\text { cidadão tenha um computador } \\
\text { em casa, Internet e que saiba } \\
\text { utilizá-lo adequadamente. É } \\
\text { preciso incentivá-lo a participar } \\
\text { politicamente pela web. } \\
\text { - Exclusão de parcelas da } \\
\text { sociedade que não possuem } \\
\text { acesso à Internet ou a baixa } \\
\text { qualidade da mesma e não } \\
\text { possuem familiaridade com o } \\
\text { uso de novas tecnologias. } \\
\text { Qualidade das informações e do } \\
\text { tipo de uso das TIC. }\end{array}$ \\
\hline
\end{tabular}

Elaboração própria com base em Castells (2004), Faria (2014), Pinho (2008; 2011), Maia (2000), Bragatto (2011), Stabile (2012), Ramos Júnior (2007) e Porwol et al. (2016).

\section{METODOLOGIA}

A classificação do estudo quanto à abordagem do problema é qualitativa e a pesquisa é de natureza exploratória. Quanto ao método adotado, é classificada como estudo de caso, uma investigação empírica que explora um fenômeno contemporâneo de maneira profunda, considerando o cenário estudado em seu contexto de mundo real, principalmente quando os limites do evento e contexto não são claros e evidentes, já que ambos não se distinguem (Yin, 2015).
O caso estudado foi o do Portal e-Democracia, gerenciado pelo Laboratório Hacker da Câmara dos Deputados em Brasília. A escolha ocorreu por conveniência - em decorrência de estágio visita realizado pelo primeiro autor do artigo na Câmara dos Deputados - e também porque o Laboratório insere-se na perspectiva de proporcionar um espaço de participação direta do cidadão nos assuntos da Câmara. A coleta de dados primários ocorreu entre julho de 2015 e janeiro de 2016, com reunião de documentos e aplicação de grupo de foco e de observação livre (Vergara, 2005).

A partir do modelo analítico, definido na revisão de literatura, para compreender algumas visões e embasar a análise de dados, foi realizada a coleta de dados primários com quatro servidores concursados que trabalham e são responsável pelo portal e--Democracia, portanto, aptos a expressar opiniões, realizar críticas e observações relevantes para o alcance dos objetivos da pesquisa. A escolha da técnica do grupo focal deveu-se ao fato de seu propósito ser intermediário entre a observação participante e a entrevista em profundidade, o que dá a ela um caráter exploratório metacientífico e compreensivista alinhado com os propósitos expressos na pesquisa (Gondin, 2003).

Os quatro servidores serão identificados como, participante $A$, participante $B$, participante $C$ e participante $D$. O participante $A$ é o que possui mais tempo de trabalho no e-Democracia e foi o contato direto desde o início deste estudo. O moderador assumiu o papel de introduzir questões norteadoras por roteiro pré-elaborado com base nas categorias identificadas no modelo analítico (TABELA 1) e ele não apresentou nenhuma opinião, mas interviu quando o debate desviava do assunto em questão. Cada categoria do modelo de análise foi abordada em sessões específicas com duração entre 20 e 30 minutos, separadas por intervalos. O moderador também fez anotações livres em diário de campo durante o período e após o término do Grupo de Foco. Por fim, o corpus de análise foi constituído das transcrições das falas dos participantes, dos documentos acessados e das anotações livres. A análise de conteúdo especialmente a sua abordagem qualitativa (Bardin, 2010) - foi conduzida como estratégia de verificação do material reunido, de modo a construir relações entre as categorias previamente elaboradas e os textos constituintes do corpus. Fragmentos dos textos foram utilizados como evidências explicativas desses grupos.

\section{ANÁLISE E DISCUSSÃO DOS RESULTADOS}

\subsection{Laboratório Hacker e e-Democracia}

Segundo Faria (2014), o portal foi criado em 3 de junho de 2009, em formato de projeto piloto, como espaço virtual interativo da Câmara dos Deputados. Seu propósito é canalizar contribuições dos cidadãos e de todos os tipos de organizações civis para a formulação de leis federais, além de colaborar com a aproximação entre a sociedade e o Estado.

O Laboratório Hacker (Labhacker) possui quatorze servidores, sendo dez efetivos, concursados e quatro terceirizados. A atuação do LabHacker tem como objetivo "articular uma rede entre parlamentares, hackers e sociedade civil que contribua para a cultura da transparência e da participação por meio da gestão de dados públicos" (Laboratório Hacker, 2015). O termo "hacker" busca dar sentido àqueles que "aplicam suas habilidades em tecnologia para interagir e desenvolver soluções criativas impulsionando a grande revolução no campo dos computadores pessoais, 
orientando-se por princípios de colaboração e compartilhamento" (Laboratório Hacker, 2015).

Após a inauguração do Laboratório Hacker em fevereiro de 2014, 0 portal e-Democracia que já existia desde 3 de junho de 2009 foi abrigado pelo laboratório. Mesmo com outras atuações, todos os dez servidores efetivos do laboratório atuam também no portal e-Democracia (Figura 1). Não há hierarquia bem definida, de modo que todos trabalham de forma dinâmica e horizontal.

Figura 1 Parte da primeira página do portal e-Democracia

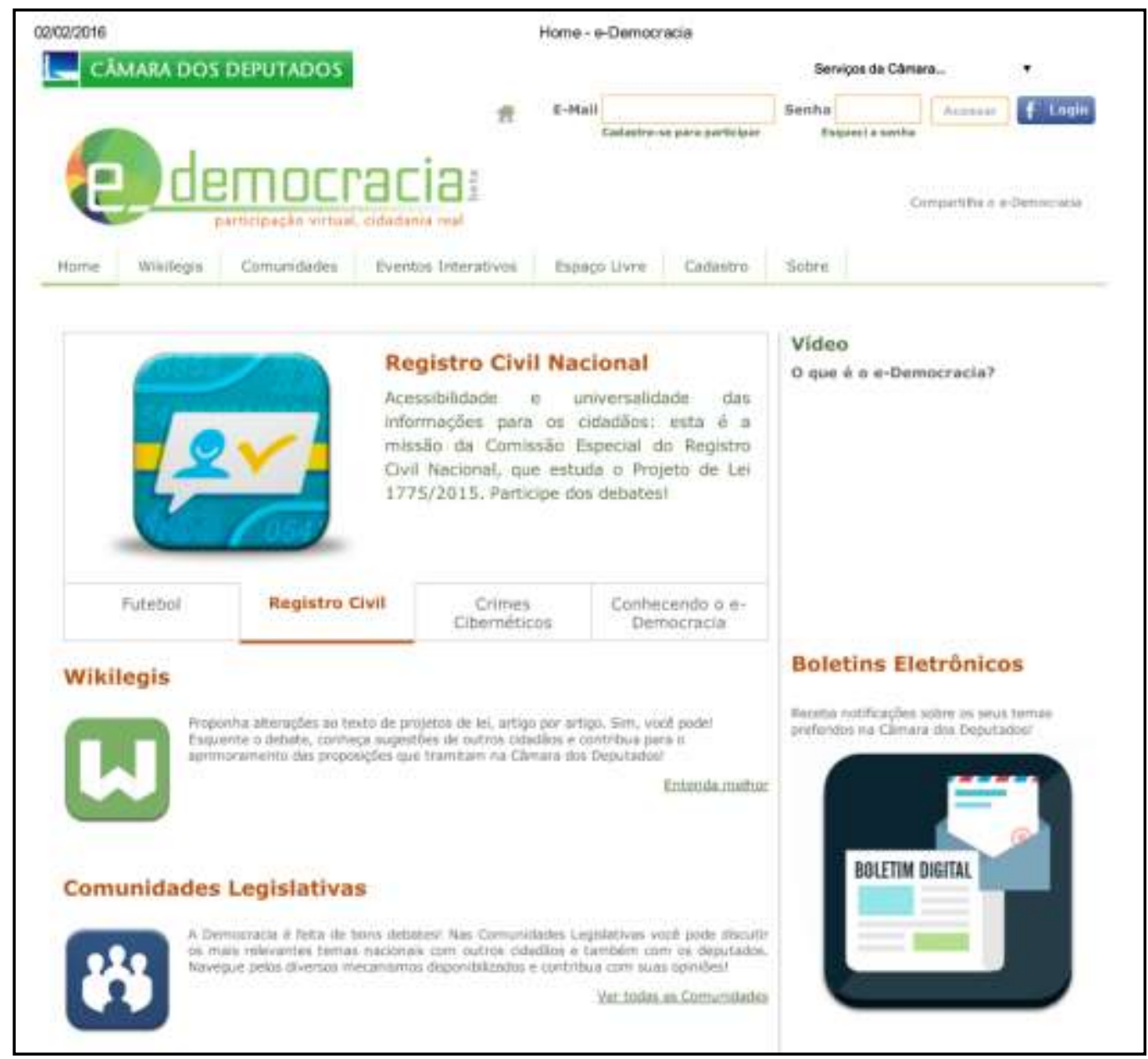

Fonte: <http://edemocracia.camara.gov.br/>. Acessado em 02/02/2016.

O e-Democracia propõe incentivar a participação da sociedade no debate sobre temas ligados ao país que cabem no parlamento e tem como objetivo melhorar e ampliar os tipos de interação entre sociedade e deputados. Existem algumas ferramentas de participação através do portal, que são as Audiências Públicas Interativas; Fóruns; Wikilegis e a Biblioteca Virtual.

As Audiências Públicas Interativas permitem aos cidadãos participarem das comissões ao vivo, podendo enviar sugestões e perguntas em tempo real para os deputados participantes, podendo ter a oportunidade de interagir com o parlamentar, caso ele acate e responda. Os Fóruns virtuais de debate constituem-se na ferramenta de maior participação, onde os cidadãos podem escolher os temas de discussão e entrar nessas comunidades temáticas para integração . Os deputados podem participar por escrito ou enviar vídeos sobre os temas discutidos, relacionando-se com os cidadãos diretamente. $O$ Wikilegis é um espaço colaborativo onde o cidadão pode de fato propor projetos de lei ou modificações em projetos de lei já existentes. nos quais cada proposta pode receber sugestões de outros participantes. Por fim, a Biblioteca Virtual é um espaço onde os integrantes podem acessar aos artigos, estudos e todos os materiais, incluindo legislações relacionadas com os temas que estão sendo debatidos no portal.

Analisando os dados do e-Democracia ao longo de 2014, pode-se apontar que os 215.258 usuáriosiii representam aproximadamente $0,11 \%$ da população brasileira. Ademais, é possível perceber a baixa atuação do portal durante 0 ano de 2014. Compreendendo o tamanho da comunidade e também os dados do tipo de uso da internet discutidos, observou-se a participação de apenas $6 \%$ dos usuários em fóruns ou consultas públicas em portais do governo e $6 \%$ em votações ou enquetes. Porém, houve crescimento de usuários, já que ao longo de 2011 o portal registrou 95.747 e apenas de janeiro até junho de 2015 houve mais de 127.000 usuários $^{i v}$. 
Figura 2 Dados de participação do portal e-Democracia do ano de 2014

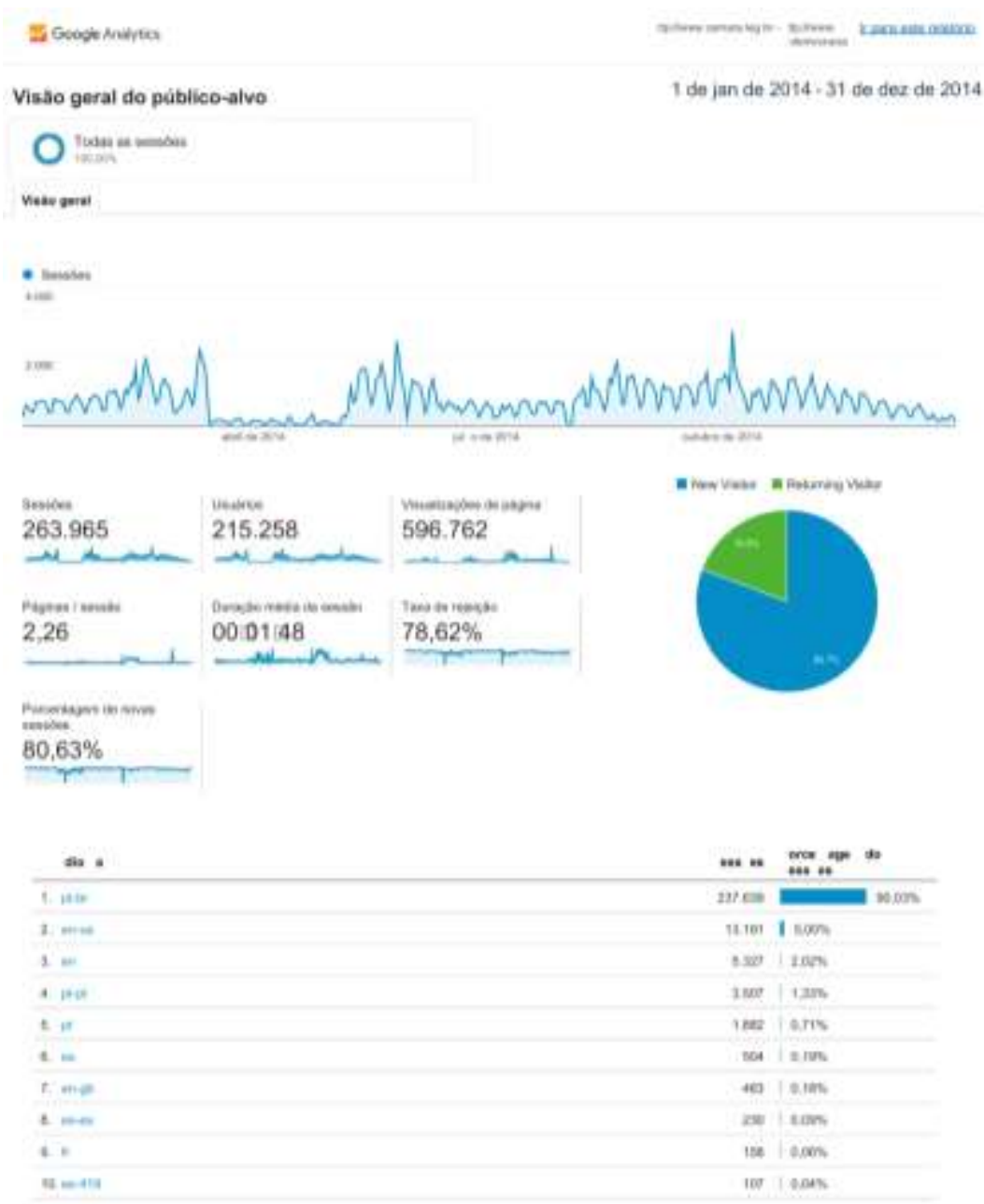

Fonte: <http://edemocracia.camara.gov.br/>. Acessado em 02/02/2016.

5.

\subsection{Participação Virtual}

O engajamento cidadão por meio da participação virtual é um requisito para o processo democrático (Porwol et al., 2016). Silva (2005) e Winkler (2009) destacam a mudança para uma comunicação mais horizontal proporcionada pelas TICs e isso poderia contribuir para o maior engajamento. Para os servidores participantes, o portal garante essa horizontalidade da comunicação, pois parlamentar e cidadão podem sugerir, opinar, propor, comentar e observar todas as ferramentas do eDemocracia.

Nessa dinâmica, quem mais participa das ferramentas do portal é a sociedade ,já que para os servidores, os governantes não disponibilizam tempo para isso, além de não haver uma legislação que regulamente isso. Segundo o Participante B, "Muitos deputados acreditam que não é função deles participar de um portal de interação com a sociedade através da Internet". Outro fator que pode explicar a não adesão dos parlamentares é idade mais avançada de alguns que não se sentem preparados para lidar com as novas tecnologias.

Freitas (2015) aponta que a democracia digital estreita a relação entre Estado e sociedade. Pode-se observar que no grupo de foco, os servidores participantes apontaram que essa aproximação não é toda verdadeira na realidade do e-Democracia, mas que é necessário um esforço para aproximar o Deputado, sociedade e os temas de discussão.
(...) a gente tem que fazer um esforço muitas vezes para conectar o deputado e 0 cidadão (...). A gente percebe que quando 0 deputado não está envolvido, surgem muitas críticas: "ah esse espaço funciona, mas cadê os deputados, onde eles estão? " $E$ às vezes a linguagem fica até um pouco agressiva. Mas a partir do momento que o deputado está presente no debate, que ele coloca um vídeo sobre a opinião dele a respeito do assunto, por exemplo, a linguagem do debate fica mais amigável, mais amena. Eu não vejo isso como verticalização do relacionamento, pra mim me parece um relacionamento respeitoso e horizontal" (PARTICIPANTE A).

Percebe-se que quando os deputados estão diretamente nos fóruns e outras ferramentas, além de conseguir aumentar a participação, eles influenciam a maneira como a população interage. Quando existe discordância sobre 0 assunto em pauta entre parlamentar e a sociedade $e$ aquele não está presente no debate, o discurso de ódio e desrespeito aumenta por parte dos presentes. Entretanto, quando o deputado participa, o cidadão mesmo não concordando e não mudando sua opinião a respeito do que está sendo debatido, ele muda seu discurso e sente-se satisfeito com a participação do governante, mostrando-se agradecido. Segundo participante $A$, "O cidadão está em busca de ser ouvido, não necessariamente ser atendido".

Pensando no intercâmbio de informações e comunicação entre sociedade e parlamentares, Castells (2004) defende que os estes são motivados a participar de ferramentas digitais para mostrarem o que querem e a sociedade só enxerga motivos de participação em temas que Ihes afetam diretamente. Nesse aspecto, os entrevistados também afirmaram que os interesses no e-Democracia são individuais tanto para os 
cidadãos quanto para os deputados. A motivação da sociedade no geral é dada por relatos de depoimentos vividos sobre os assuntos em pauta ou se os mesmos possuem conhecimento sobre o assunto profissionalmente. "Quanto mais específico o tema, mais participação tem o debate" (PARTICIPANTE D).

A única exceção dá-se em temas polêmicos nos quais o interesse é coletivo por parte da sociedade e todos possuem uma opinião sobre 0 assunto. O exemplo que deram foi de um debate sobre a união homo afetiva em que independentemente de ser uma realidade para o cidadão, ele possui sua opinião e quer demonstrar seu apoio ou discordância. Já os deputados participam de pautas que são de sua atuação ou de seu interesse sendo motivados a interagirem através do portal por esse motivo.

Os servidores chegaram à conclusão de que a participação não é satisfatória, acreditam ter potencial, mas isso não se faz suficiente para o bom funcionamento do e- -Democracia. São muitos os motivos que acreditam ser desencadeadores da não participação como falta de habilidade com as ferramentas digitais, ausência de cultura de interação e principalmente a falta de difusão do portal. Eles apontaram que não existe nenhum tipo de apoio institucional da Câmara dos Deputados para qualquer divulgação paga. Portanto o LabHacker só pode utilizar as redes sociais e os veículos de comunicação institucional da Câmara, que julgam não ter o alcance ideal para tornar mais conhecido o portal e-Democracia.

Além da divulgação externa para a sociedade, o LabHacker possui dificuldades de conseguir dialogar com todos os deputados para mostrar 0 quão interessante pode ser sua interação com a sociedade através do portal. Criou-se um material impresso resumido para mostrar quais são as possibilidades e alcance que o parlamentar pode ter participando do eDemocracia. No entanto, como afirma o Participante A, "existe um déficit gigante de participação".

No grupo de foco, foi abordada a questão se o portal é uma alternativa viável de participação realmente democrática. Para defender que o portal é democrático, os participantes apontaram que antes, apenas uma pequena e particular parcela da sociedade brasileira tinha acesso à Câmara dos Deputados em Brasília, que se restringia aos grupos de influência ou de movimentos sociais quando se mobilizam em alguma causa específica. Além do fato da participação presencial na Câmara limitar-se a oitenta pessoas no plenário sem nenhum direito de se manifestar. Para eles, com o portal, mais pessoas podem participar do processo legislativo sem barreiras de espaço e tempo, como também aponta Gomes (2005), e que agora possuem voz e podem participar e influenciar mais as ações da instituição, pois são mais visíveis aos parlamentares. Segundo os entrevistados, quem participa do portal hoje são os que possuem computadores e internet e, em sua maioria são participantes instruídos, que dominam o assunto, que se propõem a participar. Porém apontam que o eDemocracia não veio para substituir outros tipos de participação democrática, considerando importante também a sociedade estar no congresso e nas ruas para o bom funcionamento da democracia.

Há grande preocupação em tornar cada vez mais fácil o acesso ao portal, diminuindo os requisitos para participação, impedindo apenas o anonimato, pois acreditam que quando o cidadão precisa inserir uma série de dados para conseguir entrar e realizar um cadastro, isso desmotiva sua participação pela internet ou limita os que possuem dificuldade com a tecnologia, ou mesmo intimida a participação de pessoas não tão instruídas, o que acreditam ter acontecido anteriormente, quando existiam mais pré-requisitos para o cadastro.

\subsection{Informação e conteúdo}

Para os entrevistados, mesmo os parlamentares sendo incentivados a participar, não há tanta adesão ou conexão entre as ações do eDemocracia e as do gabinete do deputado. Isso decorre porque é difícil convencê-los acerca de como o portal pode ser uma ferramenta interessante para ampliar a sua relação com a sociedade que ele representa. No trecho abaixo, um dos servidores explica como ocorre a apresentação do portal aos governantes:

(...) a gente tem buscado essa conscientização por parte dos gabinetes pra ampliar 0 alcance do feedback e da participação tanto o momento anterior como o posterior da participação". (PARTICIPANTE A)

Pensando na escolha de temas dos deputados para trabalhar no portal, nem sempre sua opção é condizente com a demanda apontada pela população, já que sua preocupação é maior em trabalhar com temas de sua atuação ou interesse específico do momento. Pode-se associar essa criação de conteúdo com a participação individualista dos parlamentares citada na Participação Virtual.

O gerenciamento das informações geradas através do e-Democracia antes de existir o LabHacker, era feito por pelo menos cinco órgãos da Câmara dos Deputados, sendo a secretaria de comunicação, o centro de informática, o centro de Documento e Informação, Departamento de Comissões e a Consultoria Legislativa (Faria, 2014). Após a criação do LabHacker em 2013, os próprios servidores passaram a gerenciar o conteúdo com apoio da Consultoria Legislativa. Eles apontaram essa gestão como dificultosa, pois não possuem um método adequado para trabalhar as informações, o qual ainda é manual. Há a necessidade de automatizar as contribuições do portal para que os temas propostos pela sociedade sejam agrupados de acordo com as atuações dos deputados e para que os assuntos de discussão e os números de cada assunto sejam mais bem organizados, de modo a dar noção das demandas de forma mais eficiente.

Os entrevistados também demonstraram que não possuem critérios pré-definidos para filtros de participações consideradas ofensivas ou de conteúdos ilegais. Apesar disso, eles relataram que em três anos de atuação no e-Democracia, dos quatro servidores do LabHacker que participaram do Grupo de Foco, apenas um precisou banir um participante de um fórum de discussão, pois atestaram que enviaram mensagens para ele relatando que seu conteúdo era impróprio, mas mesmo assim ele continuou agindo de forma inadequada.

$\mathrm{Na}$ opinião dos servidores, os filtros podem desestimular ou estimular a participação. Se há moderação de algum comentário ou manifestação em ambiente majoritariamente a favor de um conteúdo impróprio, pode haver o desestímulo à interação da sociedade. Porém, o contrário também ocorre, pois ao moderar um conteúdo inadequado que não representa a maioria, isso estimula a troca de opiniões entre os cidadãos interessados, uma vez que eles acreditam que a gestão do portal está correta. O e-Democracia conta com o apoio de consultores legislativos para trabalhar com o conteúdo do portal e analisar se as propostas ferem a legislação brasileira. A partir dessa análise, é feito um retorno aos participantes por meio de mensagens privadas, quando se observa a impropriedade do assunto. No 
entanto, como observado, são raros os casos nos quais é preciso banir algum componente.

O gerenciamento das informações foi um dos aspectos mais delicados no Grupo de Foco. Houve um pouco de desconforto nesse tema por parte dos participantes, pois não existe consenso e nem metodologia sobre como os conteúdos devem ser gerenciados, especialmente quanto a conteúdos ilegais, impróprios ou ofensivos. Os servidores manifestaram preocupação em não censurar, mas também eles não podem se omitir.

\subsection{TIC e prática democrática}

Com a reorganização social devido às mudanças no ambiente político acarretado pelas TIC (Bragatto, 2011), busca-se compreender qual a influência delas na relação sociedade-governo mediada através do eDemocracia. Entretanto, os servidores destacaram que as diversas demandas devem encontrar uma espécie de ecossistema de participação.

(...) fazendo essa analise, eu tirei a conclusão que os públicos são diferenciados [portanto] devem as ferramentas serem adaptadas a esses públicos. (...) Se você tem um camarada que ele participa de fórum e você não tem fórum ele não vai usar o 0800 e então ele não vai participar, então a gente acredita que é necessário que seja criado e mantido um ecossistema de participação, e a gente até defende que esse ecossistema seja maior (PARTICIPANTE A).

(...) a questão do ecossistema existe dentro do próprio e-Democracia, a gente tem subsistemas, digamos, para públicos diferentes, o que vai usar o fórum não necessariamente vai usar o wikilegis e vice-versa. Às vezes é um cidadão que quer dar uma contribuição mais técnica e o outro quer discutir ou só votar (PARTICIPANTE D).

Foi mencionada uma ideia de como seria ideal a dinâmica para incluir os cidadãos para participar politicamente na internet com o governo de maneira mais simples, sem dar tanta atenção para aplicabilidades técnicas do governo que não são de conhecimento de todos.

(...) a ideia é que esses instrumentos de participação, e a gente acredita que eles... E dados mostram que eles fomentam muito a participação e eles tem que ser multidisciplinares de forma a trabalhar integrado e serem diversificados porque são públicos diferentes (PARTICIPANTE A)

Em toda discussão, foi abordado o fomento que deve haver na participação multidisciplinar e integrada para de fato as TIC conseguirem influenciar e melhorar a relação sociedade-governo. Percebidas a partir da perspectiva dos sistemas sociotécnicos (Porwol, et al., 2016), elas moldam essa relação ao aproximarem grupos diferentes, possibilitando dinamicidade para a relação entre o provedor e o receptor e entre a sociedade e o governo. Vistas como sistemas emergentes (Ramos JÚNIOR, 2007). elas apresentam possibilidades diversas para o ambiente político, uma vez que ele torna-se mais descentralizado, permitindo a participação de novos atores. Os entrevistados concordam que com a internet as ferramentas adequadas, pode-se incentivar e incluir diferentes públicos com novas realidades.

Um dos limites da tecnologia é não englobar toda a sociedade. Além disso, a participação no portal e-Democracia dos que possuem acesso à rede é muito baixa, o que gera baixa representação. Dentre os limites apresentados estão os culturais. Isso decorre, na interpretação dos participantes do grupo focal, da falta de costume de participação e também da desconfiança sobre a credibilidade da tecnologia dos cidadãos comuns. Da parte dos deputados, a falta de regulamentação que promova a utilização do portal é um limitador. Em relação aos limites técnicos, foram apontadas dificuldades da sociedade em entender a linguagem legislativa. Sobre esse aspecto, os participantes do grupo focal concordam acerca da necessidade de adequar os conteúdos.
Outro problema levantado pelos servidores diz respeito ao não apoio institucional da Câmara dos Deputados para a divulgação do portal, visto que não é possível fazer nenhum tipo de divulgação paga do e-Democracia. Mesmo nas mídias sociais, há dificuldades para divulgação devido à preocupação de não alinhamento com a publicidade dos gabinetes dos deputados, que possuem mais seguidores que o próprio portal.

Tabela 2 Síntese dos resultados

\begin{tabular}{|c|c|c|}
\hline Categorias & Possibilidades & Limitações \\
\hline $\begin{array}{l}\text { Participação } \\
\text { Virtual }\end{array}$ & $\begin{array}{l}\text { - Participação } \\
\text { horizontal. } \\
\text { - e-Democracia está } \\
\text { no mesmo nível de } \\
\text { outros portais em } \\
\text { outros países. }\end{array}$ & $\begin{array}{l}\text { - Baixa participação dos deputados em } \\
\text { relação à sociedade participante. } \\
\text { - Grau de aproximação entre } \\
\text { deputados, sociedade e temas } \\
\text { debatidos baixo. } \\
\text { - Falta de habilidade dos usuários com } \\
\text { ferramentas digitais e ausência de } \\
\text { cultura de participação. } \\
\text { - Falta de apoio para divulgação do } \\
\text { portal. }\end{array}$ \\
\hline $\begin{array}{l}\text { Conteúdo e } \\
\text { Informação }\end{array}$ & $\begin{array}{l}\text { - Conteúdos mais } \\
\text { ricos resultado do } \\
\text { estreitamento do } \\
\text { deputado e cidadão. } \\
\text { - Conteúdos gerados } \\
\text { por pessoas que não } \\
\text { tinham acesso à } \\
\text { Câmara. }\end{array}$ & $\begin{array}{l}\text { - Dificuldade de ampliar o fluxo de } \\
\text { informação devido a desconexão entre } \\
\text { gabinetes / e-Democracia / sociedade. } \\
\text { - Falta de automatização das } \\
\text { contribuições do público. } \\
\text { - Falta de metodologia para } \\
\text { gerenciamento dos conteúdos. }\end{array}$ \\
\hline $\begin{array}{l}\text { TIC e prática } \\
\text { democrática }\end{array}$ & \begin{tabular}{lr}
\multicolumn{2}{c}{ Dinamicidade na } \\
relação provedor- \\
receptor nos \\
ambientes virtuais. \\
- As TIC contribuem \\
para democratizar \\
acesso à câmara e \\
aumentam & e \\
conhecimento & da \\
instituição & e \\
possibilidades & de \\
participação. &
\end{tabular} & $\begin{array}{l}\text { - Limites culturais de participação em } \\
\text { ambientes como o e-Democracia } \\
\text { - Falta de interesse. } \\
\text { - Resistência a novas ferramentas de } \\
\text { interação por parte da sociedade e } \\
\text { parlamentares. } \\
\text { - Sociedade tem dificuldade da } \\
\text { compreensão do legislativo. } \\
\text { - Limites de gestão do portal e- } \\
\text { Democracia. }\end{array}$ \\
\hline
\end{tabular}

Fonte: Elaboração própria.

\section{CONSIDERAÇÕES FINAIS}

Os resultados demonstraram que o e-Democracia conseguiu criar um ambiente horizontal de interação da Câmara dos Deputados com a sociedade, ou seja, entre o cidadão e o parlamentar. Esses atores podem interagir com proposições, ou apenas observando os conteúdos ali presentes, nas diferentes formas possíveis de participação disponíveis, de acordo com o perfil de cada usuário. No entanto, nota-se que o processo democrático é enfraquecido pela falta de engajamento cidadão, que ocorre tanto no comportamento dos próprios deputados, como no da população representada por eles. Ressalta-se que esse engajamento de "mão-dupla" é necessário, pois a sociedade sente muito mais a necessidade de ser ouvida diretamente pelos próprios governantes do que atendida em todas as suas demandas.

Ademais, observou-se que quando o deputado está ausente, a linguagem do discurso altera-se para uma forma mais grosseira. Isso mostra como é difícil aproximá-lo com a sociedade e os temas diversos apresentados para discussão. Todavia, quando governantes e cidadãos participam juntos dos fóruns ou de audiências públicas interativas são gerados resultados que não seriam possíveis de outra forma, considerando o distanciamento físico desses atores. Isso tem o potencial de reorientar as ações dos parlamentares, as quais nem sempre estão alinhadas com as demandas reais da sociedade.

Percebeu-se que o gerenciamento do e-Democracia é um tema delicado, especialmente em considerando o conteúdo veiculado. Os servidores do LabHacker apresentaram dificuldades, por exemplo, com a 
falta de métodos e instrumentos de sistematização das contribuições. Eles também apresentaram problemas em relação à falta de automatização das participações do portal, o que os coloca numa condição de análise discricionária na captura e organização das informações que é limitada. 0 trabalho de organizar os conteúdos gerados no portal é totalmente humanoe essa identificação fosse pelo menos em parte automatizada, na opinião dos servidores, isso poderia tornar o processo mais eficiente e eficaz, otimizando o tempo de acesso aos temas pelos deputados e representados, tornando o engajamento desses atores mais efetivo para o processo democrático.

Outro problema foi a falta de apoio institucional para a divulgação do portal e- -Democracia e certa dificuldade de conseguir a colaboração dos gabinetes dos Deputados para isso, especialmente para não vinculá-lo à iniciativa institucional. Todavia, os servidores demonstraram acreditar no potencial da ferramenta eletrônica e no ecossistema de participação decorrente dela, o qual consegue atingir diferentes públicos de distintas maneiras adequadas a cada perfil de usuário. Pode-se considerar que o eDemocracia atinge o objetivo de ser um ambiente de fluxo do processo democrático, uma vez que possibilita a interação horizontal entre deputados e sociedade. No entanto, operar por meios instrumentais 0 conceito substantivo da democracia é um desafio e isso precisa ser mais debatido, uma vez que se corre o risco de iniciativas como a que foi aqui estudada servir apenas como ferramentas de medida da opinião pública e de promoção do marketing institucional.

Como limitações deste estudo destaca-se, principalmente, a ausência da opinião dos deputados e da sociedade. A coleta de opinião desses atores geraria informações que poderiam ser confrontadas com as dos servidores que participaram do Grupo de Foco, chegando a conclusões moldadas pelas três visões: LabHacker; deputados e sociedade. Esse entrave também abre a possibilidade de investigar iniciativas como a do eDemocracia a partir de visões distintas de usuários e gestores com base nas perspectivas discutidas neste artigo. Nessa direção, esta pesquisa levantou questões que merecem ser investigadas, como a identificação dos motivos para os parlamentares não participarem do e-Democracia e sobre os mecanismos eficientes de estímulo ao engajamento, visto que sua ausência desestimula o cidadão comum a participar e também muda o tipo de discurso da população nas ferramentas do portal. Além disso, novas investigações podem ser realizadas acerca do que a sociedade realmente espera de um portal de interação sociopolítica e se o e-Democracia atende essas expectativas.

\section{REFERÊNCIAS BIBLIOGRÁFICAS}

Alonso, A. I.; Barbeito, R. L. (2016). Does e-participation Influence and Improve Political Decision Making Processes? Evidence From a Local Government. Lex Localis-Journal of Local Self-Government, v. 14, n. 4, p. 873-891, Oct.

Abreu, J. C. A.; Pinho, J. A. G. (2014). Sentidos e significados da participação democrática através da Internet: uma análise da experiência do Orçamento Participativo Digital. Revista de Administração Pública, v. 48, n. 4, p. 821-846. Bardin, L. (2010). Análise de Conteúdo. Lisboa: Edições 70. Bonavides, Paulo. (2006). Ciência Política. São Paulo: Malheiros Editores,
Bragatto, Rachel C. (2010). Democracia e Internet: apontamentos para a sistematização dos estudos da área. Revista Compolítica, n. 2, vol. 2, ed. setembrooutubro, ano 2011. Rio de Janeiro: Compolítica,.

Brasil. Constituição (1988). Constituição da República Federativa do Brasil. Brasília, DF: Senado Federal: Centro Gráfico.

Brasil. Lei № 9.709, de 18 de novembro de 1998. Regulamenta a execução do disposto nos incisos I, II e III do art. 14 da Constituição Federal.

Castells, Manuel. (2004). A Galáxia Intenet. Edição da Fundação Calouste Gulbenkian. Lisboa, Portugal.

Carvalho, José Murilo. (1997). Mandonismo, Coronelismo: Uma discussão Conceitual. Dados, Rio de Janeiro, v. 40, n. 2.

Dahl, R. A. (2001). Sobre a Democracia. UNB,.

Dos Santos, J. U. D. L. et al. (2015). CIDADÃOS EM REDE: o gabinete digital do Estado do Rio Grande do Sul como instrumento de democracia digital. Revista Democracia Digital e Governo Eletrônico, v. 1, n. 12, p. 150-182.

Faria, Cristiano Ferri Soares de. (2014). O parlamento aberto na era da Internet: pode o povo colaborar com o Legislativo na elaboraçãodas leis? - Brasília: Centro de documentação e Informação Edições Câmara.

Freitas, C. S.; Lima, F. F.; Lima, F. Q. (2015). Desafios ao desenvolvimento de um ambiente para participação política digital: 0 caso de uma comunidade virtual legislativa do projeto e-Democracia no Brasil. Organizações \& Sociedade, v. 22, n. 75 Gil, Antônio Carlos (2002). Como elaborar projetos de pesquisa. 4. ed. - São Paulo: Atlas,.

Gomes, Wilson (2005). Internet e Participação Política em Sociedades Democráticas. Revista FAMECOS Porto Alegre $\mathrm{n}^{\circ} 27$, agosto.

Gondin, S. M . G. (2003) Grupos Focais como Técnica de Investigação Qualitativa: desafios metodológicos. Paidéia, v.12, n.24, p. 149-161.

Kneuer, M.; Harnisch, S. (2016). Diffusion of e-government and e-participation in Democracies and Autocracies. Global Policy, v. 7, n. 4, p. 548-556.

Labhacker, Revista Labhacker (2015). Câmara dos Deputados. Brasília,. 2 ed. Disponível em: http://labhackercd.net/assets/files/revista_labhacker_2ed.pdf>. Acesso em 20 de janeiro de 2016.

Maia, Rousiley C. M.Democracia e a Internet como esfera pública virtual:aproximando as condições do discurso e da deliberação.Congresso Internacional"Internet, Democracia e Bens públicos" - FAFICH/UFMG - 6 a 9 de novembro de 2000.

Pinho, José Antônio Gomes de. (2008). Investigando portais de governo eletrônico de estados no Brasil: muita tecnologia, pouca democracia. Revista de administração de empresas- Rio de Janeiro 471-93, maio/jun.

Pinho, José Antônio Gomes de. (2011). Sociedade da informação, capitalismo e sociedade civil: Reflexões sobre Política, Internet e democracia na realidade brasileira. Revista de administração de empresas, n. 01, vol. 51 ed. Janeiro-fevereiro, ano 2011. São Paulo: Administração de empresas.

Porwol, L.; Ojo, A.; Breslin, J. G. (2016). An ontology for next generation e-Participation initiatives. Government Information Quarterly, v. 33, n. 3, p. 583-594, 2016/07/01/.

Ramos Júnior, Hélio Santiago e ROVER, (2007). Aires José Democracia Eletrônica na Sociedade da Informação - XVI Congresso Nacional do CONPEDI,.

Rød, E. G.; Weidmann, N. B. (2015). Empowering activists or autocrats? The Internet in authoritarian regimes. Journal of Peace Research, v. 52, n. 3, p. 338-351.

Ribeiro, Renato Janine. (2011). A Democracia. Publifolha Rio de Janeiro

Sampaio, R. C. (2016). e-Orçamentos Participativos como iniciativas de e-solicitação: uma prospecção dos principais casos e reflexões sobre a e-Participação. Revista de Administração Pública, v. 50, n. 6, p. 937-958.

Santos, H. R.; Tonelli, D. F.; Bermejo, P. H. (2014). Sociopolitical digital interactions' maturity: analyzing the brazilian states. International Journal of Electronic Government Research, 10(4), 76-93, October-December

Silva, Sivaldo Pereira. (2005). Graus de participação democrática no uso da Internet pelos governos das capitais brasileiras. Campinas: Opinião Pública, vol. XI n02.

Stabile, Max. (2012). Democracia eletrônica para quem?: Quem são, o que querem e como os cidadãos avaliam o portal da Câmara dos Deputados. Dissertação (mestrado) Universidade de Brasília, Instituto de Ciência Política. Programa de Pós-Graduação em Ciência Política.

Vergara, S. C. (2006). Métodos de pesquisa em administração. 2. ed. São Paulo: Atlas.

Winkler, Ingrid. (2009). Internet, Democracia e Participação Política: Algumas considerações Teóricas. II Encontro de Administração da Informação. Recife 21 a 23 de junho de.

Yin, Robert K. (2015). Estudo de Caso: Planejamento e Métodos tradução: Cristhian Matheus Herrera 5. Ed. Porto Alegre: Bookman.
Registram-se agradecimentos ao CNPq pelo apoio na realização dessa pesquisa.

ii http://cetic.br/tics/usuarios/2014/total-brasil/G4/ Acessado em 1 de dezembro de 2015 iii Dados retirados do portal e-Democracia:

(http://edemocracia.camara.gov.br/documentos\#.VqElafkrLIV) com último acesso em 21/01/2016. iv Dados retirados do portal e-Democracia :

(http://edemocracia.camara.gov.br/documentos\#.VqElafkrLIV) com último acesso em 21/01/2016 